\title{
Burn this Journal!: Reconstruction, the Value of Information, and the Future of the Journal
}

\author{
Davin Heckman, Sarah Hildebrandt, R. Stewart Varner, and Matthew \\ Wolf-Meyer
}

In theory, academic publishing is about active participation in a community of scholars. In practice, academic publishing is about gaining status by getting something printed in the most static venue possible. At its worst, the Journal is an insider's club where gatekeepers tag select works for limited circulation, and scholars humbly submit to this hierarchy. For cultural studies scholars, many of whom make a great show about their "radical" politics, the limitations of the print journal should provoke some reflection. Instead of asking how we as scholars actively participate in replicating the economy of prestige at the price of knowledge, we get comfortable with the culture of the Academy. We start to believe our own hype.

As a project, Reconstruction takes its own shape as material and criticism is added, changing the meaning of what came before and creating new possibilities for things to come. Because of its collaborative nature, Reconstruction should allow us to reconsider the concept of the "organic intellectual," allowing many types of intellectuals from many traditions and non-traditions to insert themselves into academic discussion. But more importantly, Reconstruction contains the potential for intellectual projects that are themselves organic in their growth-living cultural texts which are not subject to the authority of individual scholars. As such, the concept of scholarly "authority," which is bound up in the concept of authorship, is surpassed by a vital, evolving, intellectual movement: no one voice speaks, instead there exists a chorus of articulated thought.

Davin Heckman, Sarah Hildebrandt, R. Stewart Varner, and Matthew Wolf-Meyer are the editors of the radical on-line journal Reconstruction, which can be found at www.reconstruction.ws.

Iowa Journal of Cultural Studies 1 (Spring 2002)

Copyright $(\odot 2002$ by the University of Iowa 


\section{Reconstructing Commerce}

The notion that information, and wisdom, should be paid for, as emblematized in the traditional academic journal, is utterly ridiculous, soaked in hubris, and ultimately harmful. Information, particularly that which is meant to educate and has the ability to charge its readers with insight and activity, should not only be made free, but accessible, interactive, and known. The spirit of capitalism that has infused the academic pursuits of the twentieth century must be eradicated if there is any hope for the future of scholarship, particularly as scholarship becomes, in the wake of feminism, more acutely personal in nature. And more so as scholarship works to critique the culture which has spawned it. As such, all information contained within Reconstruction, although it will retain the copyright of its author, will remain free and accessible - other journals that insist on payment will slowly atrophy and eventually fail, as their eyes and minds turn ever inward in the downward spiral of intellectual decay, while journals that impart interactivity among the contributors and the readers, in such venues as message boards and chattrooms, will flourish and become the inheritors of the intellectual potential of humanity.

Information is never free. The control of information is always political. While the information that comes through the senses during a walk through the park on a sunny day might not carry a cash value, the access to this type of information does reflect class concerns and speak to issues of access and public space. The information in the classroom is similarly charged. We can treat it like Pepsi, which can be bottled and sold to paying customers (fattening the haves and letting the have-nots go without). Or we can teach this information to those who might not be able to afford the costs (sometimes this means providing information for "free"). Poor people, deprived of everything else, don't need to be deprived of access to education, too. Few people have the luxury to devote time to this project, but that doesn't make it wrong.

Academe's steady descent into business concerns has systematically deprived scholars of their individual power while increasing the power of the university as a whole-but rather than concerning itself with a proactive intellectual politics (which the individual is more prone to enact), this power has been used to accrue money and athletic prestige. Rather than uplifting humanity through education, the university has devolved into a certification machine, supplying paying students with proper paperwork. But how can we decentralize this power network, privileging the individual scholar over the politics (or lack thereof) of the institution? Can we rethink the institute?

Because the University does not pay for intellectual work (as much as it pays for grant-winning research projects, revenue-generating athletic programs, and tuition-grabbing "credit hours"), those of us who believe that education and information is valuable for the "common good" (placing this value above that of the business transaction) are given little choice but to distribute information freely or at our own personal cost.

The realities of academic publishing can be a difficult thing for some to come to terms with: The fact of the matter is that most people are drawn to academia 
because they have a passion for intellectual pursuit-not monetary reimbursement. This is not a form of fleecing though: The University, for all its faults, does pay scholars for the writing they do, through advancement and annual bonuses. As such, the system already obviates the need for journals to pay for the work that they publish. The more and the higher the quality of the material one publishes, especially in the competitive world of academia as it is, the more likely the author is to get a well-paying and respected job.

The "problem" is that paper journals still are for-profit entities: The standard paper journal is often filled with advertisements, and subscriptions far outstrip the costs of producing the bound material. The beauty of the internet, and one of its liberating factors, is that for a nominal fee we're able to produce a journal that is freely accessed by anyone with computer access-the editors do this work as a labor of love, as do the writers. And readers presumably read it because they are honestly interested in the subject matter, and it inspires thought.

However, problems are creeping in. One of the main problems being an increasing demand for scholars to generate revenue for universities (even public ones). While at one time, it was simply enough for scholars to teach courses and write books, now we find ourselves forced to write grants, publish relentlessly, and push teaching loads onto graduate assistants who are overworked and underpaid. In the shuffle, the goal of providing students with information that is not only marketable but "enlightening" is being lost. Education was once considered to be politically liberating - it can be so again.

Where does Reconstruction fit into all of this? It's hard to say at such a critical time. Reconstruction is an effort to correct some of the politics that the University has fallen prey to. While we may not make money and cannot pay money, the Reconstruction community is an attempt to allow workers to take control of the means of production (we do not belong to an institution or press). By establishing editorial policies that attempt to move away from the business model and towards a community, trying to keep an open-minded submissions policy, and encouraging readers to become writers and writers to become readers again, Reconstruction is truly about building a new kind of University. It is so difficult to imagine a future that is not bound up in the economic and militaristic realities that we see today. The University can serve a liberatory function. Reconstruction is one possible model (in perpetual construction) for what the University can become.

With books, paper journals, and libraries, there is an enormous amount of material cost that goes into the distribution of information. With the internet, there are costs, too. Server space, computer access, software, internet service-all of these things cost money. But once these costs have been added up (for producers and consumers), we cannot justify tacking our own personal tax to line our coffers. Taking away money from someone who wants to participate in this project is not a priority.

Reconstruction is extremely conscious and aware of the many loopholes and foibles of academic publishing and is openly attempting to create and provide new alternatives for scholars. In opposition to some of the more postmodern collectives, Reconstruction has sought to maintain the rigor of serious and critical schol- 
arship. In order to foster good scholarship, it is important for academic journals to avoid giving monetary incentives to their contributors. Though not perfect, this seems like the best way to insure the quality and seriousness of academic scholarship, thereby rejecting solipsistic works with flashy titles that, despite their critical ineptitude, may sell better.

\section{Reconstructing the Scholar}

Scholars should be willing to confront the reactions of their audience, and to counter with insight and arguments of their own: information should not be dispensed, but acted out. As such, the articles that are to be found in Reconstruction are only the first part of a process of informing. Readers should feel willing, and able, to respond to the writer through our message boards and know that not only will other readers respond to them, but also the writers themselves. Education cannot happen in a void, and it is only through this form of intellectual interaction that we will be able to impart on readers a proper understanding of the project of Reconstruction and the meaning and possibilities contained within each of the intellectual efforts contained herein.

Moreover, readers should feel empowered to respond to articles with article length studies of their own. The intellectual conversation is not bettered by proselytizing.

One of the roles that an on-line journal can play is to bridge the gap between academics and non-academics. There is simply too much wisdom (both practical and theoretical) floating around in both worlds to let it drift away. Non-academics could certainly benefit from some of the more rigid and disciplined approaches to criticism that academics abide by. Academics can always benefit from a dose of humanity (if we can use the term). There is a real rift between what "scholars" do and what "non-scholars" do. This difference should not be paved over with some sort of unifying ideological asphalt. Roads should have potholes, and sidewalks should have grass growing up out of the cracks. They are signs that no matter what structures we try to impose, they are always temporary, and that life goes on. But there can be common causes. We don't have to position ourselves as an "enlightened" minority, utterly confounded by what it is that $99 \%$ of the world around us is interested in doing, believing, etc. (while eccentric positions might seem to mark us as "innovative," they could just as easily be or become positions of ignorance and irrelevance).

Some academics have applied their minds to activist work and community service. This is certainly one way to try and fix the problem. Folklorists have taken this in the other direction, listening to subjects speak for themselves.

An on-line journal can offer another way to bring the two worlds closer together. We [academics] have been crashing their parties, now it's only fair that they be invited to ours. An on-line journal can share information that is normally only reserved for University students, faculty, libraries, and bookstores.

More importantly, we can provide ways to let others shape the content of the website. A message board allows visitors to contribute content and participate in 
discussions that refer directly back to materials that have been published by "official scholars." People who have had no previous interest in academic work can get involved in online academic discussions and debates. Someday, hopefully, these people would produce "feature length" research project or book reviews. We have faith that we can build non-segregated communities.

But this does not answer the problem of how to get others involved who do not have the time or resources to produce a carefully crafted essay.

\section{Reconstruction Continues}

One of the immediate issues of this project has been the acquisition of a system of apparent politics. By this we mean that the editorial decisions behind publishing an article are as much a matter of the interest level of the subject matter being treated by the author as of a sympathetic alignment on the part of the editors affiliated with this project to the politics of the author-or the author's own apparent politics. As such, what conspires to occur is a borrowing of borrowed politics: We construct a political face out of the components given to us by others, who are themselves borrowing from other writers, who in turn have borrowed their own politics (and by "politics" we mean to imply everything from the matter of language choice to the scholarly interest of the author and his or her methodology). These are careful decisions that need to be made, for in these formative years a relationship between this journal and the world that it lives in must be founded, as well as a reputation among its readership (or potential readership): It simply wouldn't be appropriate to pigeonhole ourselves as a Marxist effort, or a psychoanalytic one, nor with any other possible theoretical concern-Reconstruction is meant to be, and will continue to be, interdisciplinary, but also inter-methodological, inter-theoretical, and inter-spatial.

It is entirely likely that a reader may encounter one of the works which we have chosen to affiliate ourselves with entirely at random (such is the nature of this internet endeavor, wherein the work can be disconnected from the journal itself), and upon such an encounter attempt to extrapolate the nature of the journal itself. Without the rubric of the journal it would be easy to see Reconstruction as a project much different than it indeed is. But this is not to say then that the content of any published work is antithetical to the politics of Reconstruction, but rather only a facet of the superstructure. The journal is an experiment in collectivity, of constant building, amendment, and change, and as such it mirrors the life of the mind, the nature of culture, the nature of consciousness.

And this is the nature of the Janus-faced journal: the likelihood of a seemingly contradictory political statement being made at some later date is very great, and this is simply because in our inter-spatiality we will work to legitimate as many political stances as seem appropriate- this may mean publishing an article that works against some earlier published work, but it is through the fusion of these political stances that some truer politics can be ascertained: There is no one method, no one politic, which will solidify all knowledge, and it is in the deliberate confusion of political statements that we may find some newer, more appropriate, truth. No 
political statement is the standard Reconstruction will adhere to: we subscribe to a deliberate state of schizophrenia, a period of eternal reconstruction.

Reconstruction, as part of a larger movement to reinvent academic publishing on-line, seeks to question the "standards" that have initiated the Humanities' long march to the margins of relevance. Where print journals (and some electronic journals) require payment for use, Reconstruction is free. Where editors refuse to publish works that are not in accordance with academic fashion, Reconstruction remains committed to a fluid ideological stance. And most importantly, where the text sits as an unassailable monolith around which scholars must arrange themselves, their work, and their opinions, Reconstruction invites readers to equal partnership in this process, through the message boards, through accessibility, and through numerous projects that invite our readers to become our writers.

Reconstruction hopes to change the way that scholarship is conducted by building new universities. 